\title{
Model Rocket Workshop: a Problem-Based Learning Experience for Engineering Students
}

\author{
J.I. Rojas, X. Prats, A. Montlaur and E. García-Berro \\ Universitat Politècnica de Catalunya (UPC), Escola Politècnica Superior de Castelldefels (EPSC), Spain
}

\begin{abstract}
A Problem-Based Learning (PBL) experience for undergraduate students of aerospace engineering is described in this paper. The experience allows the students to build a model rocket using materials which can be easily obtained. They also compute all the relevant quantities to design and characterize the rocket and they test the robustness of their design. They furthermore launch the rocket with the corresponding payload and verify the flight parameters using an on-board altimeter. Finally, they also compare the flight parameters with the theoretically expected values. Using this simple scheme the students are later introduced in the simulation of complex flows, using standard techniques. We find that our students get rapidly involved in the project, allowing them to acquire several practical abilities, besides developing an accurate knowledge of the physics of rockets and of fluid dynamics.
\end{abstract}

Index Terms-Model Rocket Workshop, Problem-Based Learning, rocketry, transversal skills.

\section{INTRODUCTION}

Graduate coursework in aerospace engineering is intended in large part to prepare students for professional practice of engineering in companies and state or international agencies and, in some cases, for postgraduate research, either in the public or private sector. Accordingly, the most complete and successful graduate programs in aerospace engineering are devised to provide a solid basis in physics and mathematics. Moreover, some topics - like, for instance, aerodynamics and flight dynamics or aeroelasticity, among others - involve an accurate knowledge of the underlying physics and a considerable load of relatively complex mathematical tools. Consequently, students quite frequently become overwhelmed by the intrinsic difficulties of these topics and, also quite usually, the success rate of regular courses is small. Furthermore, in most engineering schools and for most of the relevant topics, the assessment of student performance depends largely, or even entirely, on examinations. The traditional examinations involve usually a variety of problems that are prepared to be completed in typically two hours of work in the classroom. A consequence of this way of assessing student performance is that the problems should be easy enough for the students to be able to solve them in a limited amount of time. However, in practice such simple problems do not occur in the professional exercise of aerospace engineering.

With the growth of physics education research as a research field many initiatives are currently being developed [1]. Moreover, with the ongoing desire to improve the teaching of intrinsically complex topics using reform-based approaches, there has been an opportunity to move beyond the classical structure of engineering and physics courses to new experiences in which the students are the real and leading actors of their education. Many of these experiences involve the concept of Problem-Based Learning (PBL) [2-5]. In PBL experiences, students work in teams to explore real-world problems. In PBL experiences, students identify problems of interest to them and experiment to find solutions, as well as design complex systems that integrate engineering fundamentals in a multidisciplinary approach. Compared with conventional learning, where the students work alone and learn from textbooks or class notes, this approach has several advantages. Among these advantages a few are worth mentioning. In particular, students develop a deeper knowledge of the subject matter, increase self-direction and motivation for the particular subject, and, moreover, they attain improved research and problem-solving skills. In summary, PBL has now become a widespread teaching method in disciplines where students must learn to apply knowledge not just acquire it.

The Escola Politècnica Superior de Castelldefels (EPSC) was founded in 1991 with the clear purpose of innovating in teaching methodologies. Since then, the EPSC has achieved a solid reputation among the Spanish universities in teaching excellence. The EPSC offers two bachelor degrees in engineering. Since 1991 it has been offering a graduate degree in Electrical Engineering. This degree was initially designed taking in mind the most innovative teaching techniques at that time. For instance, most of the graduate courses have used since then fully cooperative or PBL techniques. Student performance is done using continuous assessment. Additionally, virtual campuses and interactive learning platforms were developed from the very beginning and all courses use them. Most of these techniques or tools have been subsequently used in other engineering schools or campuses of the Universitat Politècnica de Catalunya (UPC) and elsewhere. Since September 2001, a bachelor degree in Aerospace Engineering is also offered at the EPSC. When this bachelor was initially designed all the courseware (virtual campuses, assessment tools...) where already in place. However, due to the intrinsic difficulties of some of the topics to be taught a more classical approach was originally adopted.

In this paper we present a new activity which has been proposed within the framework of a teaching unit dealing with experimental techniques in Aerospace Engineering. This subject is included in the last year of the degree and it is aimed to complement and intensify all the theoretical aspects that have been already taught during the whole 
bachelor degree. In this context, different and independent practical works are performed by the students within the teaching unit. In particular, the activity presented in this paper consists in designing, constructing, launching and analyzing the flight parameters of a small model rocket by using cooperative and PBL techniques. The paper is organized as follows. In section 2 we describe the course goals. In section 3 we discuss the course organization. Section 4 is devoted to describe the methodology, the managerial issues, and the material and methods needed to deliver the course. Special attention is given on how student assessment is done. In section 5 the course results are described. Finally, in section 6 we summarize our major findings and conclusions are drawn.

\section{COURSE GOALS}

Our objectives in designing the teaching unit were that students should learn the most relevant concepts of the problem at the appropriate deep level, become familiar with best practices research-based tools and materials, and gain insight into how engineers think about real research problems. These objectives are consistent with those of the bachelor in Aerospace Engineering program at the EPSC. We also wanted the students to practice other skills that are highly desirable in their professional field. Accordingly, during the Model Rocket Workshop (MRW) the students are expected to work as they would do as engineers in a professional environment, where solutions of specific problems are formulated, planned and developed. Hence, during the workshop, some theoretical aspects related with aerospace technology (propulsion, aerodynamics and mechanics) are given but, at the same time, students are expected to develop several transversal skills such as team working, project management, leadership, problem-solving skills, oral and written communication and self-learning.

\section{COURSE ORGANIZATION}

At the beginning of the activity, several teams are formed depending on the number of students. Typically the teams are constituted by 4 or 5 students. In the particular case of the first MRW session at EPSC, 25 students split into 5 groups were participating. The teaching staff for this session was constituted of 4 people (the authors: a professor and 3 teaching assistants), although we believe that the activity can be conducted by 2 or 3 people without a problem. The members of each group will work together in the development of a model rocket which must fulfill some specific technical requirements which are given in advance. Firstly, the flight trajectory of a generic model rocket is theoretically computed and simulated by integrating numerically the equations of motion. The students develop themselves the algorithms, the numerical tools and the corresponding software. Then, the model rocket itself is designed and constructed using simple and common materials and pieces that can be usually found for amateur or recreational uses. The simulations are updated with the final rocket real data. Before launching the models, the rocket must pass several tests with the purpose of assuring some basic safety aspects, such as rocket stability or adequate structural strength. A launch campaign is then designed and executed. The altitude versus time is recorded by means of a mini-altimeter placed inside the nose fairing of the rocket (emulating a hypothetical payload that must be safely recovered after the launch). Finally, the measured trajectory is compared with the theoretical one and conclusions are drawn and publicly presented by the members of the team to the teaching staff and students.

\section{COURSE DESCRIPTION}

\section{A. Methodology and Course Design}

The MRW learning methodology is mainly inspired on a well-known technique called Groups Puzzle - see [6] and references therein - in which the entire subject of study is divided in several equivalent parts (or pieces) which are assigned to different students or teams of students within the team. When working on a given part, the assigned students must meet with the members of the other groups which are dealing with the same part, thus creating a set of parallel groups. These groups are often called "expert groups". Once the experts have finished their task and fulfilled the particular goals of their role, they return to their original main group in order to transfer the acquired knowledge to the rest of the members. Therefore, a significant part of the teaching process is actually performed by the students among themselves. As a consequence, once the entire process is finished, each individual of the main group should be able to understand the whole problem and develop a solution to solve it. Therefore, the success of a main group means a success of all its members.

\section{B. Course Management}

A web-based project management platform is used by all teams. The open-source software called dotProject ${ }^{1}$ is used for this purpose. This platform provides some basic applications for project management such as task organization and planning, human and material resources allocation, project progress utilities and several others. In this way, the members of each team can organize their work, share files, communicate and coordinate efforts, as it would be done in a real professional environment. In addition, due to its on-line architecture, dotProject offers a file repository module, several mail notifications, a forum application to discuss the progress of their duties or even to interact with members of other teams. Hence, this utility provides a suitable combination for learning project management concepts and, at the same time, plenty of cooperative, interactive and remote features that support the whole learning process. Being hosted in one server of the computer center of the EPSC, all students and teaching staff involved in the MRW can login to dotProject from any computer connected to the internet using a conventional web browser. Therefore, this platform can be also used by the students to interact with the instructors for eventual questions, as well as by the academic staff in charge of monitoring the status of the tasks assigned to each group of students. 


\section{Materials}

Table 1 shows a list of the equipment and materials needed to complete the whole teaching unit. As can be seen, most of these items are inexpensive and readily available at regular stores, whereas others can be purchased either in specialized stores or directly from the manufacturers. In particular, we purchased the rocket motors, fuselages and nose fairing to a specialized manufacturer.

\section{Description of the Experience}

As previously explained, the so-called Groups Puzzle formative methodological strategy was used as basic reference to design the activity. Nevertheless, certain features of this methodology have been slightly changed in to make it more suitable to the nature of the subject and to the teaching goals previously stated. The workshop lasts for twelve sessions approximately. A Gantt Diagram showing the MRW schedule is shown in Fig. 1. The planning is strict and clearly fixes procedures and deadlines for all the groups. Several milestones are placed along the project, as well as the deadlines to deliver the partial reports and results. During the first session, after the presentation of the workshop, the teaching staff assumes the role of a client company and provides the students with information regarding the requirements to be fulfilled by the mission and other useful information such as, for example, the rocket engine thrust profile - which is provided graphically by the manufacturer of the rocket engines. From this moment, each basic group is supposed to constitute a project group of a space agency, in charge of planning and accomplishing the design, construction and launching of the rocket, taking into account the mission requirements that the instructors have already issued. All the tasks and duties are clearly indicated in Fig. 1. As can be seen, the students perform first the mission analysis. Subsequently they start the launch preparation, shortly followed by the rocket development. Finally the rocket is certificated and ultimately it is launched. Once the payload (the altimeter) is recovered, the flight parameters are analyzed and compared to the theoretical expectations. The software needed to download and process the flight data acquired and stored by the altimeters is provided by the manufacturer of the altimeters.

All data and information that can be useful for the students is loaded and available in the dotProject platform. For instance, the students find from the very beginning the rocket motor performances and features, the safety code for rocket launching, and many other documents. All documents are written in English and the whole teaching unit is also delivered in English. The reason for that is to create an environment with the highest degree of realism, that is, as similar as possible to that found in international agencies or aerospace companies.

When designing the MRW, it was decided that the basic groups were to be constituted of four members, although this number can be made larger if desired, as will be explained later. Therefore, according to the Groups Puzzle methodology, the subject was divided into four main tasks. Again, aiming to simulate as close as possible the real environment of a space agency or an aerospace company, the task distribution inside every group is done as it occurs in real space agencies. This is the reason why the following four roles or types of experts were identified, each one associated to clearly defined responsibilities and duties:

\section{- Mission engineer:}

Coordinates all other tasks and experts, solves the rocket flight equations and presents the overall results, once the workshop has finished, during the last session

- Development engineer:

Designs the rocket and leads its construction

- Test engineer:

Prepares and supervises the certification tests of the own rocket and performs the tests of the rockets of a different group

- Launch engineer:

Elaborates the rocket launching procedures thought to guarantee safety and ignites the rocket at the launching ramp

The activity can be suited to allow basic groups composed of more than four members. To achieve this, the list above can be extended with additional roles, according to the standards of the industry.

TABLE I.

INVENTORY OF EQUIPMENT AND MATERIALS NEEDED TO PERFORM THE ACTIVITY

\begin{tabular}{|l|c|c|}
\hline \hline \multicolumn{1}{|c|}{ Item description } & Quantity & Reusable \\
\hline Altimeter & 5 & Yes \\
\hline Launch ramp & 1 & Yes \\
\hline Igniter & 1 & Yes \\
\hline Anemometer & 1 & Yes \\
\hline Cutter & 5 & Yes \\
\hline Saw & 5 & Yes \\
\hline Walkie-talkie & 4 & Yes \\
\hline Ruler & 5 & Yes \\
\hline Bubble level & 5 & Yes \\
\hline Silicone gun & 5 & Yes \\
\hline Scissor & 5 & Yes \\
\hline Domestic scale & 1 & Yes \\
\hline Measuring tape & 5 & Yes \\
\hline Rocket motor & 10 & No \\
\hline Nose fairing & 7 & No \\
\hline Fuselage & 7 & No \\
\hline Non-flammable cotton & 1 & No \\
\hline Silicone tube & 5 & No \\
\hline Glue & 5 & No \\
\hline Thermal sheet & 3 & No \\
\hline Adhesive tape & 2 & No \\
\hline Cord roll & 2 & No \\
\hline Wood & 2 & No \\
\hline Painting spray & 5 & No \\
\hline \hline
\end{tabular}




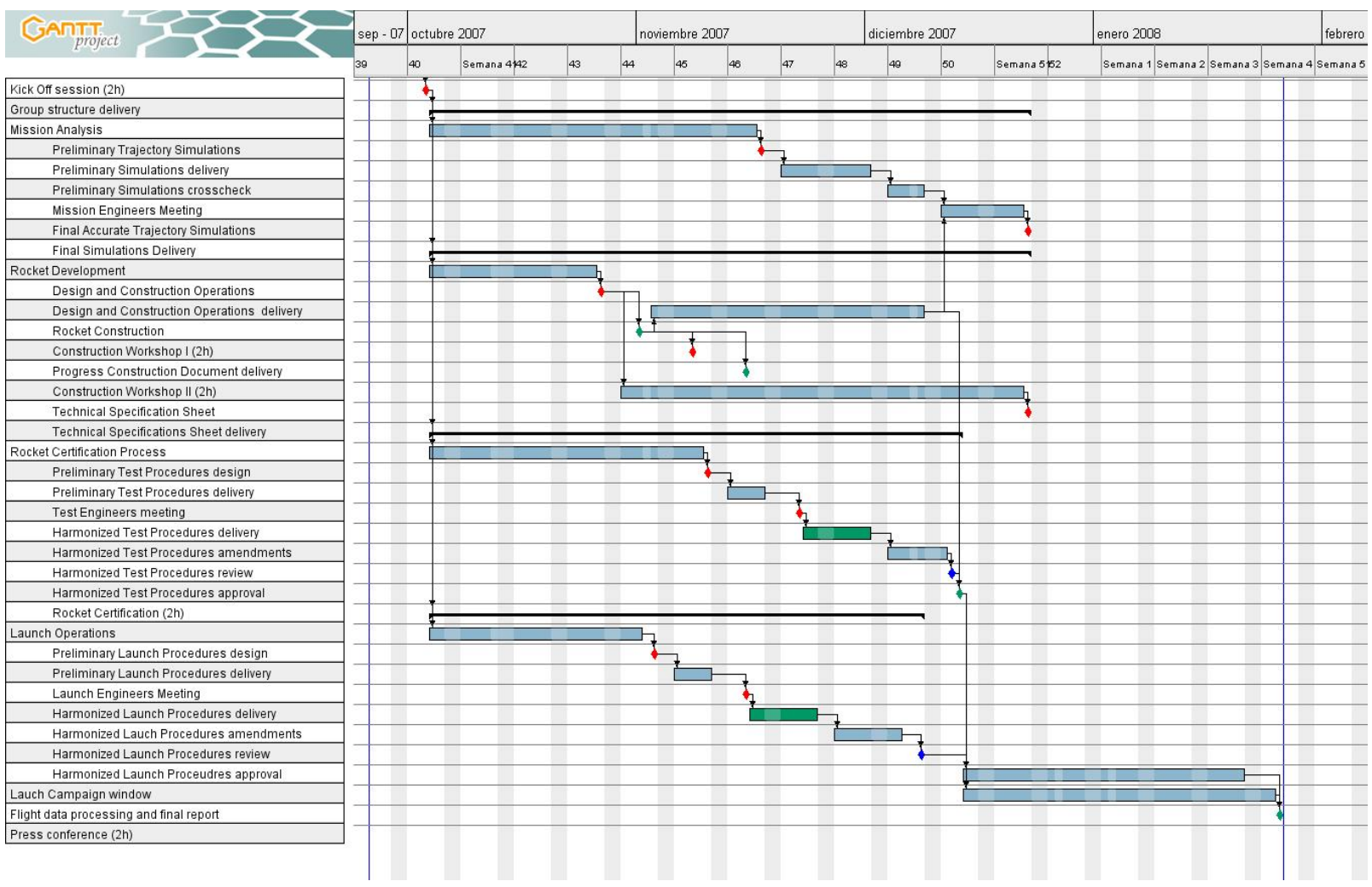

Figure 1. Gantt Diagram showing the Model Rocket Workshop schedule

Along the workshop several basic group meetings and expert groups meetings take place, besides the individual work of each student. For example, the meeting to share out the main roles - which, in fact, corresponds to the first session without the instructors - as well as the meetings to share acquired knowledge and transfer results to the rest of the members of the team, belong to the former class of meetings. The first contact between experts aiming to identify their main tasks and responsibilities, the problems involved in designing and building the rocket and other issues - which, in turn, corresponds to the second nonactual session - is to be included in the latter type of meetings, the expert meetings. Both classes of meetings are fundamental to guarantee the proper performance of the tasks, which demand a high level of interaction between group members. This is due to the existence of a strong interdependence as regards to the data and results, inputs and outputs of those tasks. In order to ensure that the expert groups meetings are more profitable and productive and to have at disposal of the teaching staff information to evaluate in a continuous way the tasks of the students, experts are demanded to deliver, prior to the meetings, brief and concise reports about the work they have done on the matters to be considered in the corresponding meeting. After some of these meetings, also the minutes of the meeting are requested, stating the work done during the meeting and the achieved milestones.

The work done by each basic group materializes into four partial reports and a final report, which must be delivered before the previously defined deadlines, as shown in Fig. 1. Should a group not deliver a report prior to the previously established deadline the instructors can deny the launching permission for the model rocket of that group. The delivery of the reports is done through the dotProject platform, where the basic group members can load the files containing their respective reports. In chronological order, the partial reports to be delivered are the following.

- Preliminary and final trajectory simulation reports: These reports must include a complete set of calculations encompassing the rocket altitude, velocity and acceleration as a function of time, obtained by integrating the rocket flight equation numerically:

$$
\frac{d M \vec{v}}{d t}-(\vec{v}+\vec{u}) \frac{d M}{d t}=\vec{F}
$$

where $M$ is the total mass of the rocket, $\vec{v}$ the velocity of the rocket, $t$ is the time, $\vec{u}$ the exhaust gas velocity and $\vec{F}$ the sum of all external forces, which, in turn, can be written in for each launch phase $i$ as:

$$
\begin{gathered}
\vec{F}_{1}=\vec{T}+\vec{D}_{1}+\vec{W} \\
\vec{F}_{2}=\vec{D}_{2}+\vec{W} \\
\vec{F}_{3}=\vec{D}_{3}+\vec{W}
\end{gathered} .
$$

where $\vec{D}_{i}$ is the aerodynamic drag in the phase $i, \vec{T}$ is the engine thrust (a plot of $\vec{T}$ versus time provided by the manufacturer of the rocket motors is given to the students) and $\vec{W}$ is the weight of the rocket (which is also a function of time). The different phases are defined as follows. The first phase corresponds to the initial climb with the engine fully operative. The second phase corresponds to the climb when the fuel of the rocket motor is exhausted. Finally, the third phase is the descending phase (parachute gliding). Fig. 
2, 3 and 4 show some pictures of the different phases. The students integrate the equations of motion using the widely known commercial software packages Matlab $^{\circledR}$ or Maple ${ }^{\circledR}$, at their choice

- Rocket design and construction operations report and technical specification sheet: These reports includ the rocket plans and construction schedule. The first one must be delivered the day before the basic groups begin the construction of the model rocket

- Preliminary and harmonized test procedures: These reports summarize the rocket certification tests design and schedule. The rocket must fulfill a set of certification requirements previously provided to guarantee a safe launching and flight. The harmonized report must be delivered the day the rocket certification is scheduled. It can only be elaborated once the final trajectory simulations updated with the data of the already built rocket are known. The preliminary trajectory simulations (which constitute the first report) have been obtained as a first approach since most of the data come from estimations because the rocket has not been designed nor built yet. All these tasks require a high level of communication and team work between basic group members

- Preliminary and harmonized launch procedures: The procedures must always satisfy rocket launching safety code disposals

Finally, the final report is delivered during the last session. This report summarizes the work done by the basic group along the workshop and includes the processing of the experimental data that the altimeter on board the rocket has acquired during the flight and the comparison of these data with the trajectory simulations of the previous reports.

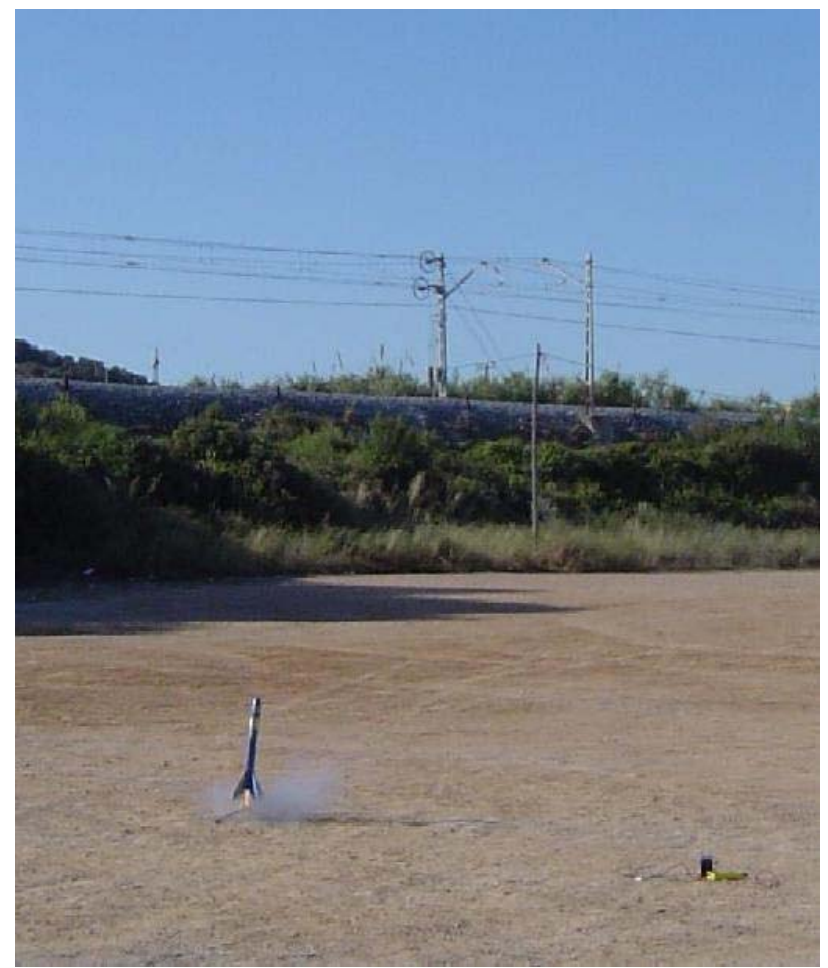

Figure 2. Ignition of the motor and lift-off of one of the model rockets

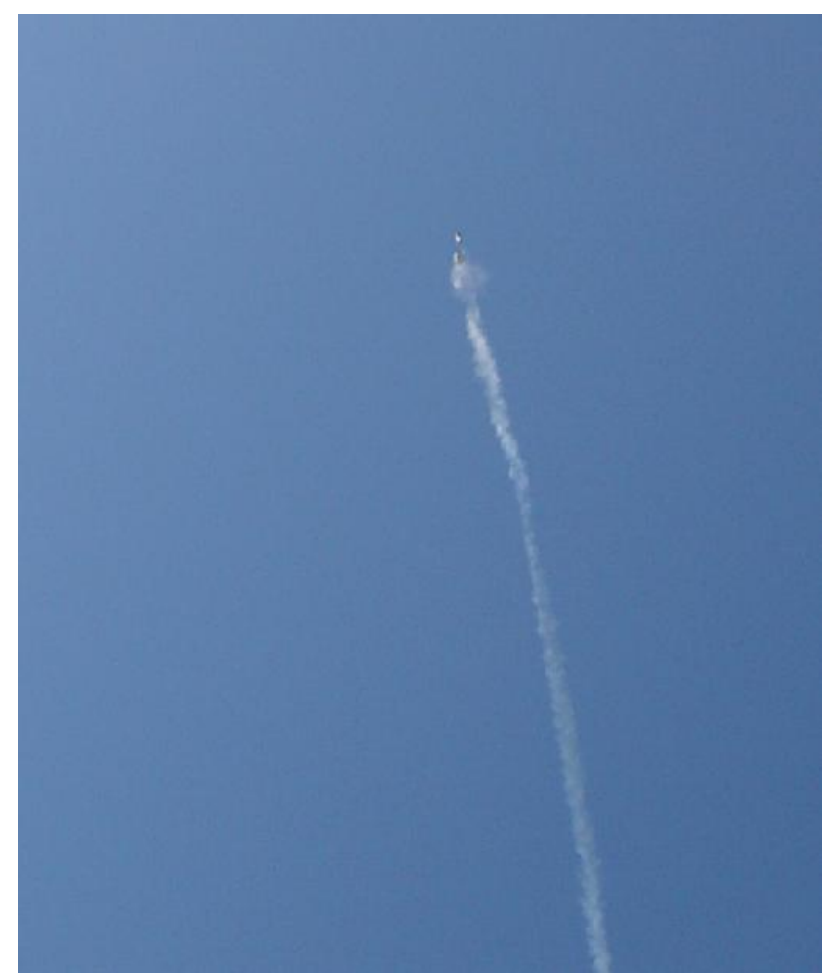

Figure 3. Rocket in the ascending flight phase with the engine operative (phase 1)

In addition, during the final session, each basic group gave a formal presentation to show its work to the rest of students and teaching staff. Following the presentation, the team members were asked about technical, managerial and team performance issues.

\section{E. Student Assessment}

The whole teaching staff is responsible for assessing student performance. Grading a PBL experience is a difficult matter but should be practical at the same time [7, 8]. Two factors must be taken into account. On the one hand, recognition must be given to the achievements of the team as a whole. On the other, the individual contributions to the team result must also be acknowledged. Additionally, it must be taken into account that each student must be graded individually. It is important to realize that pure team-based assessment might be a disadvantage to the stronger students and equally be misused by weaker students and that the grade should reflect the evolution of the student during the workshop. Hence, the student is encouraged to carry on a portfolio in which each individual student documents all the work already done. In addition to this, the several reports delivered during the teaching unit are also graded. Since each of the students is in charge of fixed duties and responsibilities, an individual grade can be assigned to each of them, although the reports are collective. The minutes of the meetings also help in assessing student performances. Finally, the results of self-evaluations and peer reviews that are done at the end of the project also provide very valuable information on the attitude, performance and functioning of each team member. These peer reviews are done both by the teaching staff and by the rest of their teammates. 


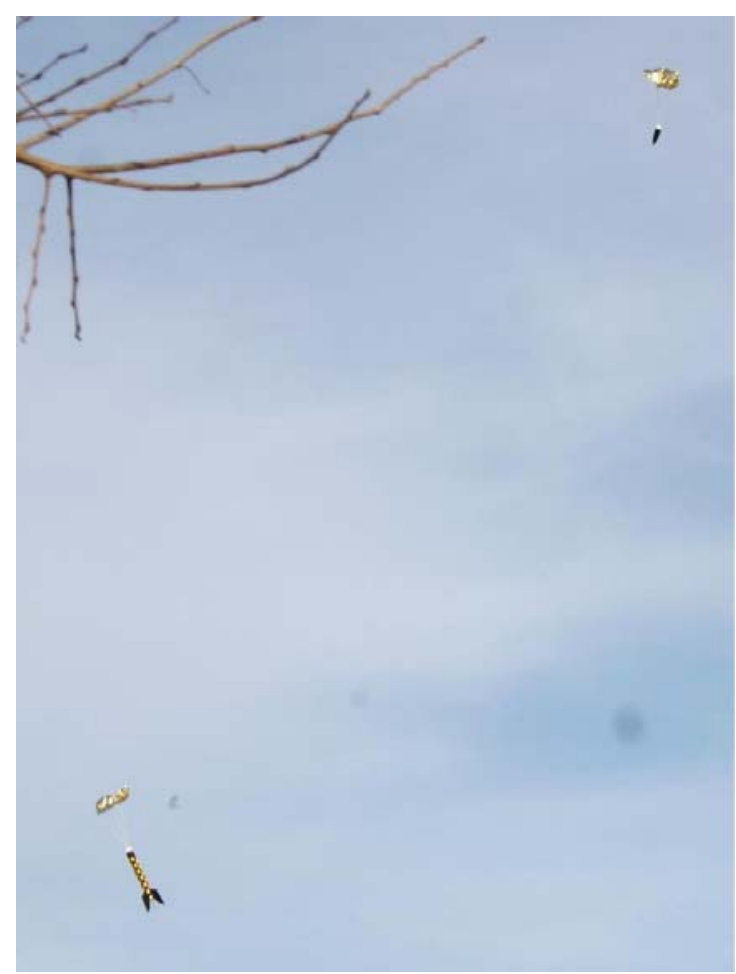

Figure 4. Descending phase (phase 3): nose fairing and fuselage are recovered separately

In this way all the members of a team rate all members of the team including themselves confidentially, on a series of concise questions ${ }^{2}$. The list of questions includes, for instance, if a given team member attended all team meetings and contributed to the activities, met deadlines by the team, helped in keeping the team organized, cohesive, and progressing toward completion of the goals... and several others. We implemented a mixture of team and individual assessment techniques, assigning $40 \%$ of the marks for group work, $30 \%$ for individual work and $30 \%$ for peer review.

\section{COURSE RESUlts}

The model rockets were launched from a site located in the vicinity of the University Campus. Permission had been asked earlier both to the City Council and to the owner of the launch site. In the present case, these two kinds of permits were the only ones needed to fly model rockets. Furthermore, according to Spanish regulations, no special permit from the Civil Aviation Authority is needed, since the site is outside any area controlled by the Air Traffic Management (ATM) and the maximum altitude reached by the rockets is below 1000 feet (the maximum allowable altitude above ground level for unmanned flying devices in Spain). The maximum flight altitude had been previously computed by integrating numerically the equation of motion and was confirmed by the experimental flight. No license is necessary neither to use the rocket motors given that D-category motors were used and that a license is only compulsory when using $\mathrm{H}$ category motors or above. Fig. 2 shows the ignition of one of the model rockets and the beginning of the vertical take-off, whereas Fig. 3 shows the rocket reaching the end

${ }^{2}$ Team evaluation form courtesy of Jim Morgan (Texas A\&M University): http://clte.asu.edu/active/team.htm of the propulsive segment (phase 1). On the other hand, Fig. 4 shows the recovery phase, where the fuselage and the nose fairing, containing the altimeter, descend separately with their parachutes.

All the models were successfully launched and recovered, though the opening of some of the parachutes was delayed causing the rocket pieces to fall faster than desired. Even though, all altimeters were safely retrieved and its flight data could be downloaded to a computer. Fig. 5 illustrates the plot of altitude of the model (in feet) versus time (in seconds), using the information of the onboard altimeter. In Fig. 6, an example of the results obtained by the students is presented. The results were obtained after numerical integration of the theoretical motion equations of the flight of a generic model rocket.

The results shown in this figure are the vertical position versus time. Usually there are significant discrepancies between the experimental results and those obtained numerically. Thus, the students are forced to imagine where these differences come from. The largest differences arise mainly from the fact that the simulations are performed with input data corresponding to a generic model rocket, whereas the final rockets differ noticeably from the generic model in several important data, among which perhaps the most important ones are lift-off weight and wind conditions.

In addition, it is worth mentioning that other interesting possibilities are currently taken into account as an expansion of the current rocket model workshop. For instance, the realization of additional calculations of rocket flight performances with specific software - like the Rocket Simulator ${ }^{3}$, a free web based model rocket simulator. Results obtained using this method can be compared with the results obtained with the previously mentioned numerical integrations done. This possibility is offered to the students and we have found that a sizeable fraction of students (of the order of $80 \%$ ) usually accept this possibility. This confirms that the students become rapidly involved in the activity.

A second possibility is the realization of simulations with commercial Computational Fluid Dynamics (CFD) software ${ }^{4}$. This possibility very much improves the educational output of the MRW but requires a stronger commitment of the students. Nevertheless we have also found that a significant fraction of the students become involved in this additional activity. CFD simulations provide redundant and complementary information on the performances of the rocket and undoubtedly benefit the characterization of the model rockets. 


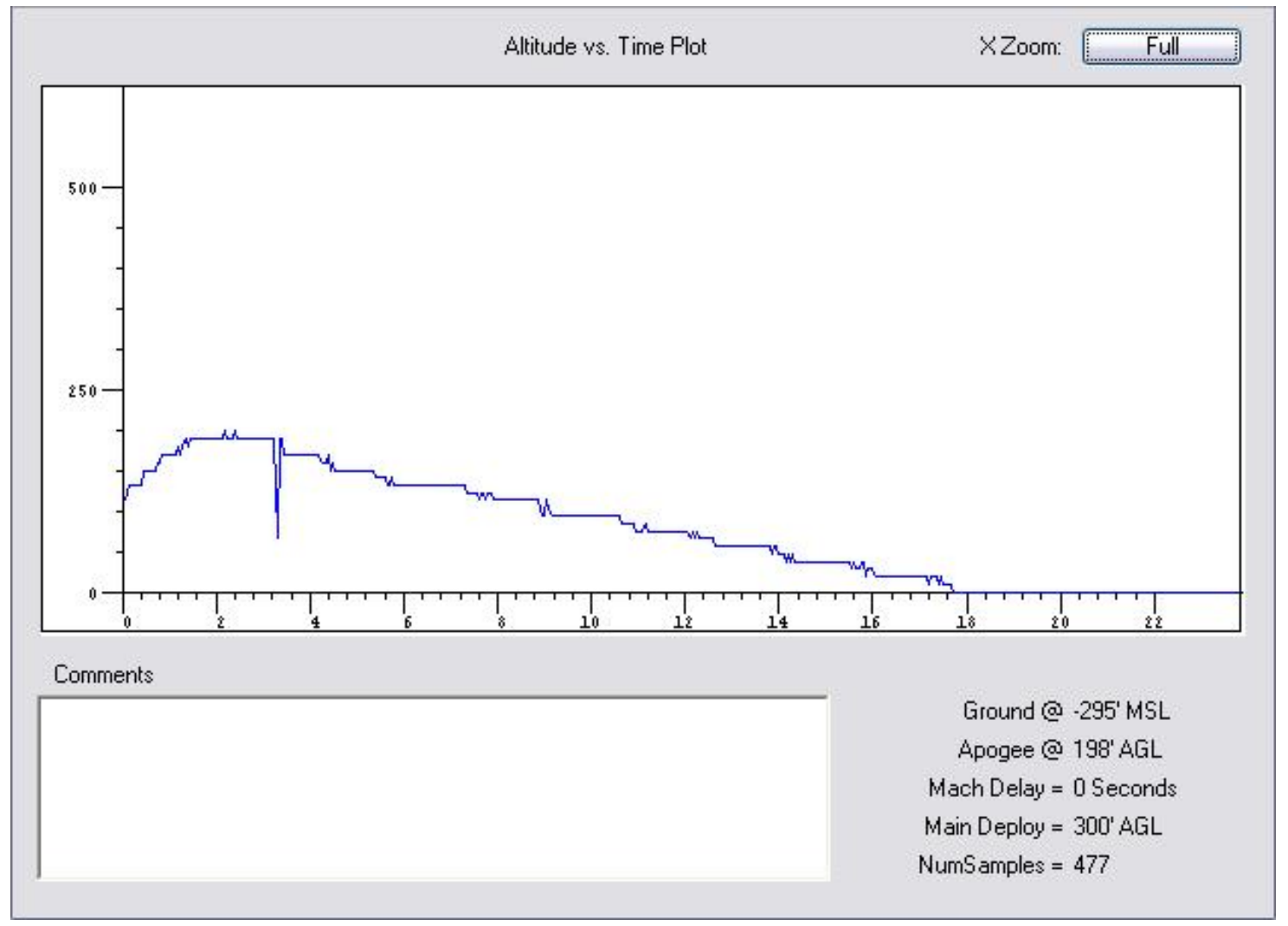

Figure 5. Plot of altitude (in feet) versus time (in seconds) extracted from the data acquired by one of the altimeters

\section{SUMMARY AND CONCLUSIONS}

In this paper we have described a Problem-Based Learning activity that has been proposed and successfully implemented within the Aerospace Engineering Program of the Universitat Politècnica de Catalunya. This activity consists in designing, building and launching a model rocket. We call it Model Rocket Workshop. This workshop allowed the students to become familiar with the development and with the different phases of a space mission. It had them debating to choose among the possible roles proposed by the teaching staff which one fitted best their personal abilities and tastes. The groups were organized in a satisfactory way and all students assumed their roles with coherent means. Furthermore the students were able to realistically experiment the compromises between power, weight and consumption, as if they had had to face these choices and achieve these tasks in a real space agency. They had as well to synthesize and publicly expose the results obtained with the project. Besides, they learned to work at request and under pressure from the customer, analyzing its requirements and comparing and adapting them to the demanded technical characteristics. Eventually they also learned security rules and quality control techniques that would have been otherwise difficult to acquire within a purely academic framework. Even the reaction of the students to the workshop was quite satisfactory. For example, some of the comments of the students were "fascinating", "enlightening", "exciting" and so on. For future editions of this teaching unit we plan to ask for anonymous student feedback.
However, in informal discussions with the students we have found that all of them consider this experience an essential component of the course on experimental techniques and that the workshop was an important component of the aerospace engineering curriculum. All in all, we consider that this PBL teaching unit has been very successful.

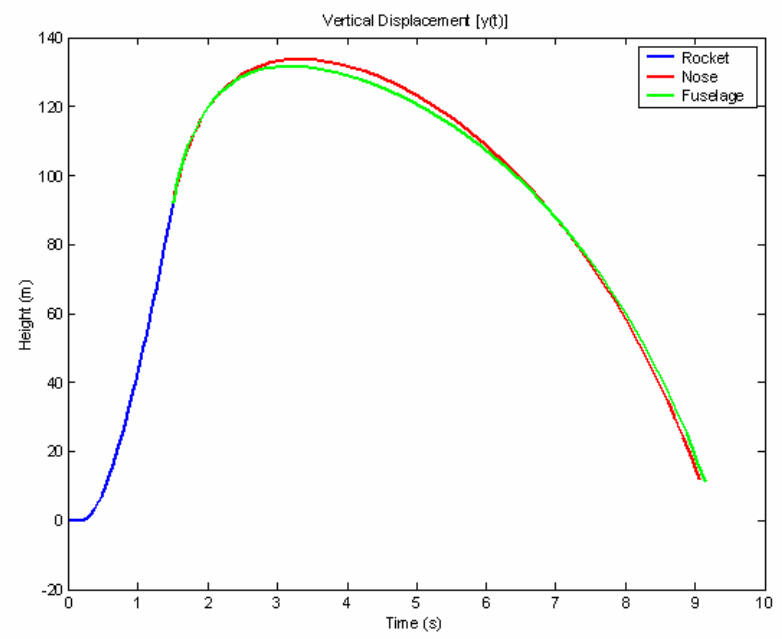

Figure 6. Flight altitude simulation for one of the model rockets 


\section{ACKNOWLEDGMENT}

The Authors thank M. Valero for his useful comments about how to organize the experience and for encouraging support.

\section{REFERENCES}

[1] D. R. Brodeur, P. W. Young, and K. B. Blair, Problem-Based Learning in Aerospace Engineering, Proceedings of the 2002 American Society for Engineering Education Annual Conference \& Exposition, 2202.

[2] L. Wilkerson and W. H. Gijselaers (Eds.), Bringing ProblemBased Learning to Higher Education: Theory and Practice, New Directions for Teaching and Learning, No. 68, Jossey-Bass, San Francisco, CA, 1996.

[3] D.Boud and G. I. Feletti (Eds.), The Challenge of Problem-Based Learning, 2nd Ed., Kogan Page, London, 1997.

[4] W. H. Gijselaers, Connecting Problem-Based Practices with Educational Theory, in Wilkerson, L, and W. H. Gijselaers (Eds.), Bringing Problem-Based Learning to Higher Education: Theory and Practice, New Directions for Teaching and Learning, No. 68, Jossey-Bass, San Francisco, CA, 1996.

[5] R. Delisle, How to Use Problem-Based Learning in the Classroom, Association for Supervision and Curriculum Development, Alexandria, VA, 1997.

[6] C. Freeman and H. Jigsaw, A Case Study Technique Where Students Become Experts, Journal of College Science Teaching, 1994.

[7] V. Brügemann et al., An Example of Active Learning in Aerospace Engineering, Proceedings of the Fifth international workshop on Active Learning in Engineering Education. Delft, The Netherlands, June 8-11, 2005.

[8] Y. Doppelt, Assessment of Project-Based Learning in a MECHATRONICS Context, Journal of Technology Education, 16,2005

\section{AUTHORS}

J. I. Rojas received his degree in Aerospace Engineering from the Universidad Politécnica de Madrid (ETSIA-UPM), in Madrid (Spain) in 2004. In 2006 he received a master degree in Aerospace Science and Technology from the UPC. He is currently pursuing a Ph.D. in Aerospace Engineering at the UPC in the field of Non-destructive Testing (NDT) of aerospace materials. In addition, he is currently performing research activities in the field of aerodynamics and in applications of spaceand ground-based technologies for the improvement of the earthquake disaster management. He has actively collaborated in the design of the vertical wind tunnel of the UPC at the premises of the Escola Politècnica Superior de Castelldefels (EPSC-UPC). He is Assistant Professor at EPSC-UPC (Avda. del Canal Olímpic, 15, 08860,
Castelldefels, Spain) since the year 2005 (e-mail: rojas@fa.upc.edu).

X. Prats earned his degree in Telecommunications Engineering from the UPC, in Barcelona (Spain). He also has a master degree in Civil Aviation engineering from the French National School for Civil Aviation (ENAC), in Toulouse (France). He is currently pursuing a Ph.D. in Aerospace Engineering at the UPC in the field of aircraft trajectory optimization and works as Assistant Professor at Escola Politècnica Superior de Castelldefels (EPSC-UPC) since 2002. His research interests are air traffic management issues as well as the study of new Unmanned Air Vehicles (UAVs) technologies in order to use them in civil non-segregated airspace (e-mail: xavier.prats@upc.edu).

A. Montlaur earned her degree in Aerospace Engineering from the École Nationale Supérieure d'Ingénieurs de Constructions Aéronautiques (ENSICA), in Toulouse (France) in 2002. She also has a Master degree in Mechanical Engineering from the State University of New York at Buffalo (2003). She is pursuing a Ph.D. in Aerospace Engineering at the UPC in the field of Computational Fluid Dynamics, and has also actively collaborated in the design of the vertical wind tunnel of the UPC at the premises of the Escola Politècnica Superior de Castelldefels (EPSC-UPC). She is Assistant Professor at EPSC-UPC since 2004 (e-mail: adeline.de.montlaur@upc.edu).

E. García-Berro earned his Ph.D. in Astrophysics from the University of Barcelona in 1987. He has been Postdoctoral Research Associate at the University of Illinois at Urbana-Champaign. He is Professor at the Department of Applied Physics of the UPC since 1991. $\mathrm{He}$ is also Research Associate of the Institute for Space Studies of Catalonia (IEEC) since 1996. His research interests have a broad scope ranging from theoretical astrophysics to the design and implementation of scientific payloads for astronomical satellites. He has published more than 80 papers in refereed journals. He was Director of the Department of Applied Physics from 1997 to 2001. He is currently Vice-rector of Quality Assessment of the UPC (e-mail: garcia@fa.upc.edu).

Manuscript received 02 May 2008. Published as submitted by the authors.

This work was supported in part by the Spanish Ministerio de Educación y Ciencia (MEC) grant AYA05-08013-C03-01, by the European Union FEDER funds and by the AGAUR. 